\title{
Erratum to: Resveratrol and red wine, healthy heart and longevity
}

\author{
Dipak K. Das $\cdot$ Subhendu Mukherjee $\cdot$ \\ Diptarka Ray
}

Published online: 13 March 2011

(C) Springer Science+Business Media, LLC 2011

\begin{abstract}
Resveratrol, a polyphenol phytoalexin, present in red wine and grapes possesses diverse biochemical and physiological properties, including estrogenic, antiplatelet, and anti-inflammatory properties as well as a wide range of health benefits ranging from chemoprevention to cardioprotection. Recently, several studies described resveratrol as an anti-aging compound. This review focuses on the anti-aging aspects of resveratrol, the possible mechanisms of action, and emerging controversy on its life-prolonging ability. It appears that resveratrol can induce the expression of several longevity genes including Sirt1, Sirt3, Sirt4, FoxO1, Foxo3a and PBEF and prevent aging-related decline in cardiovascular function including cholesterol level and inflammatory response, but it is unable to affect actual survival or life span of mice.
\end{abstract}

Keywords Resveratrol · Red wine - White wine . Cardioprotection · Longevity genes · Anti-aging · SIRT $\cdot$ FoxO $\cdot$ PBEF

$\begin{array}{ll}\text { Abbreviations } \\ \text { SIRT } & \text { Sirtuins. } \\ \text { FoxO } & \text { Forkhead transcription factor. } \\ \text { PBEF } & \text { Pre B cell colony enhancing factor. } \\ \text { LDL } & \text { Low-density lipoprotein. } \\ \text { BMR } & \text { Basal metabolic rate. } \\ \text { CR } & \text { Calorie restriction. }\end{array}$

The online version of the original article can be found under doi:10.1007/s10741-010-9163-9.

D. K. Das $(\bowtie) \cdot$ S. Mukherjee · D. Ray

Cardiovacular Research Center, University of Connecticut

School of Medicine, Farmington, CT 06030-1110, USA

e-mail: ddas@neuron.uchc.edu

$\begin{array}{ll}\text { IGF1 } & \text { Insulin-dependent growth factor } 1 \\ \text { ROS } & \text { Reactive oxygen species } \\ \text { NOS } & \text { Nitric oxide synthase } \\ \text { VEGF } & \text { Vascular endothelial growth factor } \\ \text { GLUT } & \text { Glucose transporter type } 4 \\ \text { PUFA } & \text { Polyunsaturated fatty acids } \\ \text { HO-1 } & \text { Heme oxygenase-1 } \\ \text { PKC } & \text { Protein kinase C } \\ \text { PI3 kinase } & \text { Phosphatidylinositol-3-kinase } \\ \text { LPS } & \text { Lipopolysaccharide } \\ \text { PGE2 } & \text { Prostaglandin E2 } \\ \text { TNF } \alpha & \text { Tumor necrosis factor } \alpha\end{array}$

\section{Introduction}

Resveratrol, a phytoalexin polyphenol that is found naturally in the grape skins and red wines, possesses diverse health benefits ranging from chemoprevention to cardioprotection. Although red wines are generally recognized as the source of resveratrol, actual resveratrol content of resveratrol is very low and varies from wine to wine [1]. Commercially, resveratrol is manufactured from Polygonum cuspidatum, a giant knotweed belonging to the Polygonaceae family, and cultivated mainly in China and Japan (popularly known as Ko-J-Kon in Japan). In addition to red wine and grape, a large variety of fruits including mulberry, bilberry, cranberry and blueberry as well as peanut contain resveratrol.

Although resveratrol has been used from time immemorial, the name became popular after the discovery of French paradox, which described cardioprotective properties of red wine [2]. Subsequent studies determined that resveratrol present in red wine possesses numerous health 
benefits including cardioprotection [3]. A majority of its cardioprotective properties are associated with its ability to exert vasorelaxation, anti-inflammatory response and ROS scavenging. It is believed that cardioprotective ability of resveratrol is linked with its ability to induce preconditioning [4]. Among other health benefits, resveratrol possesses antitumor activity [5] and neuroprotective abilities [6].

Recently, a number of studies described resveratrol as an anti-aging compound. The first study came from the Harvard Medical School and Biomol Research Laboratories, which reported in a revolutionary discovery that resveratrol could activate anti-aging gene SIRT1 [7]. Based on the animal study, the authors noted that depending on the concentration of resveratrol present in red wine, one needs to consume several bottles of red wine per day to get such a dose [8]. Subsequent studies found that resveratrol in a very small dose could activate not only Sirt 1 but also Sirt 3 and Sirt 4 as well as FoxOs and PBEF, all being linked with longevity proteins [9]. Interestingly enough, this study found that in addition to red wine and resveratrol, white wine and its components tyrosol and hydroxytyrosol could also activate the same longevity genes suggesting that activation of Sirtl could be a non-specific phenomenon. A recent study reported that resveratrol prevented age-related and obesity-related cardiovascular functional decline in mice, but did not affect the overall survival or maximum life span for mice on a standard diet, compared to mice on the same diet with resveratrol [10].

The word longevity means life expectancy in demography, but in general term this word means long life. In contrast, aging is a process that contributes to health deterioration decline in productivity, disability and ultimately to death with time. Since chronic diseases like coronary heart disease, cancer, etc. are the major causes of death, and nutrition plays a key role in the fight against these degenerative diseases, it can also be assumed that nutrition plays a key role in expanding life span too. Proper diets containing a proper variety of grains, fruits, vegetables and foods low in saturated fat, trans fat and cholesterol protect human beings from several degenerative diseases. Of course, nobody can ever be immortal, but they can definitely invigorate their short life span and lead a healthy life, free from diseases and disorders. Proper nutrition is essential for health; people who are well nourished are more likely to be healthy, productive and live long. Efforts were put on this direction from time immemorial, and many ancient sacred texts point the necessity for a balanced diet constituting of fruits and vegetables with proper amount of beverages in maintaining the individual health and acquiring a longer life span. Nowadays, with the rapid development of material science, the introspective human mind started to try to find the reason behind such age-old instructions. With the rise of diabetes, obesity-related organ failures and deaths; people should be much more conscious regarding their health by not only doing daily physical exercise but also by disciplining dietary habit. This is particularly true for the elderly people because the incidence of heart failure increases with age. The risk factors for heart attack rapidly increase for the people 65 and older. In a multicenter longitudinal cohort study in elderly Americans, it was found that the prevalence of chronic congestive heart failure ranged from 12 to $25 \%$ for women 65-85 years old, and from 19 to $32 \%$ for men in the same age range [11]. The risk factor for heart failure among the elderly consists of multiple causes including hypertension, diabetes and obesity. Healthy life style and intelligent choice of food are likely to reduce the risk factors.

The body has a tendency to store extra amount of nutrients as fat in the belly region that a healthy diet can prevent. Conscious calorie intake and calculated burning can do a really remarkable job in this direction. Calorie restriction (CR) should not be confused with malnutrition nor with deliberate starvation as the former can lead to anemia, muscle loss, dizziness, lethargy, nausea and the latter slows down the metabolism rate a lot, resulting in a decrease in weight loss. Caloric restriction (CR) helps improving the age-related health degeneration as evidenced in some rodents and fungi [12].

CR has been shown to lower cholesterol, fasting glucose and blood pressure in human subjects. In CR, energy intake is minimized, but sufficient quantities of vitamins, minerals and other important nutrients containing no calories must be swallowed, through pills if necessary. Decrease in Basal Metabolic Rate (BMR) is the foremost observation from calorie-restricted diet group [12]. Also, a long-term CR brings in lesser amount of LDL cholesterol and a simultaneous increase in HDL cholesterol, controlled blood pressure both systolic and diastolic, fasting glucose, fasting insulin, significantly low triglyceride level, better body mass index and body fat percentage [12,13]. Perhaps, the system of fasting or maintaining a controlled diet chart in some holy month or day came out after deep observations of the effects of CR. A good diet mimicking CR can manipulate the effect of CR on the serum levels of insulindependent growth factor 1 (IGF 1) as seen in rodents [14]. Good diet activates the survival proteins and suppresses the expression of pro-apoptotic proteins when the system is in vulnerable condition. It triggers the anti-oxidant mechanism to scavenge the free radicals in both the initial and the later phases and thus protects the system, heals the discord and induces longevity.

Several studies have shown that resveratrol, a phytoalexin, obtained from grape skin can mimic the effect of caloric restriction and extend life span. In this review, we 
Table 1 Resveratrol content of selected fruits and vegetables

\begin{tabular}{lll}
\hline No & Foods & Resveratrol/cup serving in $\mathrm{mg}$ \\
\hline 1. & Blueberry & $\sim 32 \mathrm{ng} / \mathrm{gm}$ \\
2. & Bilberries & $\sim 16 \mathrm{ng} / \mathrm{g}$ \\
3. & Cranberry raw juice & $\sim 0.2 \mathrm{mg} / \mathrm{L}$ \\
4. & Mulberry & $\sim 0.0021-0.0053 \mathrm{mg} / \mathrm{g}$ \\
5. & Peanuts (raw) & $\sim 0.01-0.26$ (per serving of $146 \mathrm{gm})$ \\
6. & Peanuts (boiled) & $\sim 0.32-1.28($ per serving of $180 \mathrm{gm})$ \\
7. & Peanut butter & $\sim 0.04-0.13$ (per serving of $258 \mathrm{gm})$ \\
8. & Red grapes & $\sim 0.24-1.25$ (per serving of $160 \mathrm{gm})$ \\
9. & Red grape juice (Spanish) & $\sim 0.17-1.30$ (per serving in a $5 \mathrm{oz}$ glass) \\
\hline
\end{tabular}

Table 2 Resveratrol content of wines

\begin{tabular}{llll}
\hline No & Wines & Total resveratrol $(\mathrm{mg} / \mathrm{L})$ & Total resveratrol/5 oz glass \\
\hline 1. & White wine(Spanish) & $\sim 0.05-1.80$ & $\sim 0.01-0.27$ \\
2. & Rose wine (Spanish) & $\sim 0.43-3.52$ & $\sim 0.06-0.53$ \\
3. & Red wine (Spanish) & $\sim 1.92-12.59$ & $\sim 0.29-1.89$ \\
4. & Red wine (Global) & $\sim 1.98-7.13$ & $\sim 0.30-1.07$ \\
5. & Pinot noir & $\sim 0.0-2.0$ & $\sim 0.06-0.30$ \\
6. & Italian red wine & $\sim 8.63-24.84 \mu \mathrm{mol} / \mathrm{L}$ & $\sim 1.30-3.75 \mu \mathrm{mol}$ \\
7. & Chilean Merlots wine & $\sim 2.25$ & $\sim 0.35$ \\
\hline
\end{tabular}

will discuss resveratrol and its ability to expand life span from molecular viewpoint.

\section{Chemistry of resveratrol}

Resveratrol belongs to stilbene family of compounds that consist of two aromatic rings joined by a methylene bridge. IUPAC (International Union of Pure and Applied Chemistry) nomenclature for resveratrol is 3,4',5-trihydroxystilbene, although it is also known as 3,4',5-stilbenetriol with a chemical formula $\mathrm{C}_{14} \mathrm{H}_{12} \mathrm{O}_{3}$ and molecular weight of $228.25 \mathrm{D}_{\mathrm{a}}$. Resveratrol exists as both cis- and trans- isoforms, but the action of the later isoform has been widely investigated. The trans isomer possesses greater biological activity due to the presence of the $4^{\prime}$-hydroxystyryl group.

Resveratrol is a naturally occurring phytoalexin, which is produced in response to an injury, such as mechanical trauma, UV light and infection by pathogenic microorganisms such as fungi. It is formed via a condensation reaction between three molecules of malonyl CoA and one molecule of 4-coumaroyl $\mathrm{CoA}$ catalyzed by resveratrol synthase that also produces four molecules of $\mathrm{CO}_{2}$.

\section{Resveratrol and health benefits}

Grape is well known in medicinal science from time immemorial. In Ayurveda, one of the ancient medicinal books of Hindus, and in the Bible, grape juice was described as cardiotonic and as a gift of god. Resveratrol is present in grape skin. Its chemical name is trans-3,5,
4 '-trihydroxy stilbene. Resveratrol exists in two isomeric form cis and trans resveratrol. Because of its higher reactivity and anticancer, anti-inflammatory, blood sugarlowering properties, trans resveratrol drew the attention of scientist worldwide. However, resveratrol is not only found in grape skin, it is also present in cranberry, mulberry, lingberry, bilberry, jackfruit, peanut gnetum, and the butterfly orchid tree (Table 1). Red wine also contains resveratrol, also its content vary from wine to wine (Table 2). External stimuli such as fungal attack and UV radiation activate the synthesis of resveratrol.

\section{Cardiovascular benefits of resveratrol}

It is now well known that resveratrol protects human health by diverse mechanisms. Mild-to-moderate wine drinking has been linked with reduced cardiovascular, cerebrovascular and peripheral vascular risks as well as reduced risk due to cancer (Fig. 1). On the other hand, French people, in spite of taking high-fat diet regularly, are less susceptible to risk factors of cardiovascular diseases, because of the presence of moderate amount of wine in their diet $[2,15]$. This phenomenon is known as the French paradox. Certain wines, grape juices, especially grape skins can provide cardioprotective effects due to the presence of resveratrol. Resveratrol is a natural anti-oxidant; it can scavenge some intracellular reactive oxygen species (ROS). It has been shown that resveratrol induces NO synthesis in case of ischemic reperfused heart, brain and kidney and lower the oxidative stress [16, 17]. Results from the available 


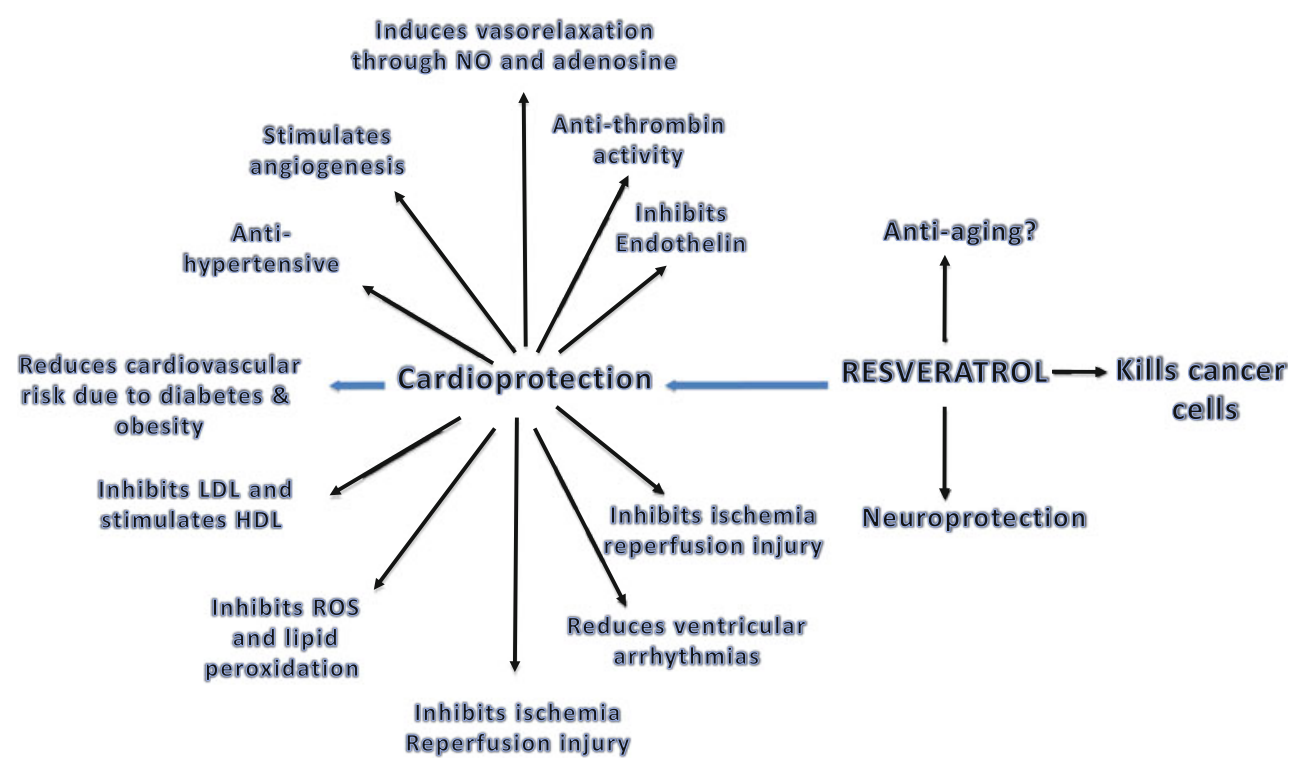

Fig. 1 Diverse health benefits of resveratrol including cardioprotection

literature show that resveratrol protects perfused rat hearts through increased iNOS expression [16, 18]. It is also shown that resveratrol provides cardioprotection via upregulation of catalase activity in the myocardium. Resveratrol has been found to pharmacologically precondition hearts by a nitric oxide (NO)-dependent mechanism [16, 18]. Das et al. [19] showed that resveratrol-induced preconditioning was derived through the upregulation of iNOS-VEGF-KDReNOS signaling cascade. A number of studies have successfully demonstrated that in the rat myocardial infarction (MI) model, resveratrol significantly upregulates the protein expression profiles of vascular endothelial growth factor (VEGF) and its tyrosine kinase receptor Flk-1 which in turn ameliorates myocardial damage [20]. Several studies from our laboratory have shown that resveratrol protects mammalian hearts from ischemia/reperfusion-induced injury evidenced by improvement on postischemic ventricular function, reduction in myocardial infarction and cardiomyocyte apoptosis, activation of survival signal, reduction of death signal $[19,21-25]$. It has been also shown that resveratrol increased GLUT-4 expression and reduced endothelin expression in ischemic-reperfused hearts of Zucker obese rats in the presence or absence of glucose intake [26], indicating that resveratrol could provide protection against obesity-related cardiac injury.

Resveratrol regulates the redox homeostasis in mammalian system by maintaining the amounts of several antioxidant enzymes, including glutathione peroxidase, glutathione- $S$-transferase and glutathione reductase [27]. It is also known that resveratrol prevents LDL oxidation [28]. There is evidence that resveratrol is a potent inhibitor of the oxidation of polyunsaturated fatty acids (PUFA) found in LDL [29]. In fact, resveratrol was shown to be more potent than flavonoids in preventing copper-catalyzed oxidation, thus preventing oxidative modification of LDL [28]. Hebbar et al. [30] showed that high doses (0.3, 1.0 and $3.0 \mathrm{~g} / \mathrm{kg}$ day) of resveratrol upregulate phase II and anti-oxidant genes in female and male rats. Due to high rate of oxygen consumption and low levels of anti-oxidant defense enzymes, the brain and the heart are particularly vulnerable to hypoxic conditions and oxidative stress injuries. Heme oxygenase -1 (HO-1) has been shown to be neuroprotective [31]; it degrades the pro-oxidant heme into biliverdin/bilirubin, iron and carbon monoxide. Bilirubin can scavenge free radicals. Carbon monoxide is a cell cycle modulator and vasodilator. It has been reported that $\mathrm{CO}$ provides anti-inflammatory and anti-apoptotic effects via $\mathrm{NF} \kappa \mathrm{B}$ regulation [32]. Resveratrol induces $\mathrm{HO}-1$ in primary neuronal cultures [33] and aortic smooth muscle cells [34] at low concentrations (1-10 mM). At higher concentrations $(>20 \mathrm{mM}), \mathrm{NF} \kappa \mathrm{B}$ activation was suppressed, and HO-1 was inhibited. Moderate resveratrol or red wine rich in resveratrol intake (presumably low concentration) could, therefore, have a considerable neuroprotective and vasculoprotective effect against oxidative stress.

Resveratrol inhibits platelet aggregation, another major contribution in the process of atherosclerosis [35, 36]. Platelets through the activation of the process of thrombus formation and their aggregation could set into motion the process of vascular occlusion. A dose-dependent decrease in platelet aggregation was shown with resveratrol treatment [37]. Resveratrol ( 0.15 and 0.25 micromole/l) was shown to inhibit collagen-induced platelet activation accompanied by $\left[\mathrm{Ca}^{+2}\right]$ immobilization, thromboxane $\mathrm{A} 2$ formation, phosphoinositide breakdown and protein kinase C (PKC) activation [38]. 
In summary, resveratrol has been found to exert cardioprotective effects by pre-conditioning the heart in addition to its ability to reduce oxidative stress developed during the reperfusion of the ischemic heart. As shown in Fig. 1, resveratrol is effective against hypertension, heart failure, cardiomyopathy, atherosclerosis, diabetes and obesity as well as against many other cardiac dysfunctions. More recently, resveratrol has been found to induce autophagy in the ischemic myocardium. Resveratrol at lower doses $(0.1$ and $1 \mu \mathrm{M}$ in $\mathrm{H} 9 \mathrm{c} 2$ cardiac myoblast cells and $2.5 \mathrm{mg} / \mathrm{kg} / \mathrm{day}$ in rat) induced autophagy shown by enhanced formation of autophagosomes and its component LC3II after hypoxia/re-oxygenation or ischemia/reperfusion [39]. Since aging is now recognized to be directly related to autophagy, which decreases with age, it seems reasonable to speculate that resveratrol is somehow related to the cardiac dysfunction associated with the aging process.

\section{Other health benefits of resveratrol}

Resveratrol has been shown to possess potential anticancer activity in various cancer cells at the initiation, promotion and progression stages. For example, high-dose resveratrol $(50 \mathrm{mM})$ has been shown to induce cell death in mouse xenograft models of human neuroblastoma cells (SHSY5Y, NGP and SK-N-AS) [40]. Moreover, 48-h exposure of $100 \mathrm{mM}$ resveratrol induced cell death in human colorectal cancer cells (DLD1 and HT29 cells) [41]. Inhibitory effects of resveratrol against breast cancer progression has been reported in both estrogen-positive (MCF-7) and estrogen-negative (MDA-MB-231) breast cancer cells as a result of $1 \mu \mathrm{M}$ resveratrol treatment in vitro and in nude mice inoculated with any of these cell lines. Ten mg per kg body weight (BW) resveratrol treatment for 2 days reduced the cancer progression [42]. Resveratrol is also well known to possess anticancer properties in animal model. It was shown that $625 \mathrm{mg} / \mathrm{kg}$ body wt resveratrol treatment reduced the progression of prostate cancer in transgenic adenocarcinoma prostate (TRAMP) mice [43]. Bhardwaj et al. [44] showed that $50 \mathrm{uM}$ resveratrol could reduce the proliferation of human multiple myeloma. Most of its anticancer properties attributes to its ability to induce apoptosis in cancer cells [41, 44-47]. For example, resveratrol induces loss of mitochondrial membrane potential, leading to release of cytochrome C and Smac/Diablo, and subsequent activation of caspase- 9 and caspase- 3 [40, 48]. In addition to these mechanisms, resveratrol can also induce cell cycle arrest at G0/G1 phase and reduce the expression of cell growth factors in human prostate cancer cell lines $[40,48]$. Resveratrol was also shown to activate pro-apoptotic Bax, p53 and p21waf in T-cell acute lymphoblastic leukemia cells [49], reduced the levels of anti-apoptotic Bcl-xL, Bcl-2, cyclin D1 and TNF receptorassociated factor [44, 48, 50]. In case of human breast cancer cells, resveratrol inhibited the anti-apoptotic phosphatidylinositol 3'-kinase (PI3 K)/Akt pathway [51] and activated the Forkhead transcription factor (FOXO3a) [42], which mediate cellular apoptosis through the activation of proapoptotic genes [42]. In addition, in earlier studies, resveratrol had been proposed to downregulate the expression of tumorigenic nuclear factor $\mathrm{NF} \kappa \mathrm{B}$ and its regulated proapoptotic gene products as well as growth factors in multiple myeloma cells [46].

In addition to its anticancer activity, resveratrol has displayed beneficial activity against inflammatory responses via the inhibition of COX1 and COX2 expression [52]. Resveratrol was reported to reduce the production of prostaglandin E2 (PGE2) and the formation of ROS in lipopolysaccharide (LPS)-activated microglial cells [53, 54]. Moreover, resveratrol was reported to suppress the activity of T- and B-cells, and macrophages [55]. Singh et al. [56] showed that resveratrol induced both caspasedependent and caspase-independent apoptosis in activated T-cells in experimental allergic encephalomyelitis-induced mice. One study from our own laboratory showed that resveratrol possesses analgesic property by the inhibition of COX1 and COX 2 [57].

Resveratrol also possesses neuroprotective properties. It has been reported that resveratrol could protect against Huntington's disease [58], Alzheimer's disease [59] and Parkinson's disease [60].

\section{Resveratrol and longevity}

Resveratrol is one of the main longevity nutrients which can mimic the effects of calorie restriction which includes expanded life span, improved tissue pathology, increased endurance, mitochondrial biogenesis, energy expenditure and insulin sensitivity, and decreased fat accumulation, blood insulin and IGF-1 [61, 72]. A significant number of reports exist in the literature indicating that resveratrol can activate the longevity assurance genes, Sirtuins (SirTs) [62-66]. Resveratrol was initially reported to increase the activity of SIRT1 in vitro [67]. Despite the uncertainty of how resveratrol functions in vitro, in vivo it extend the life span in Drosophila [68] and C. elegans [69] Resveratrol also increases the life span of vertebrates such as Nothobranchius furzeri, a shortlived seasonal fish, and delays its age-dependent degenerations [70]. It is now well known that in mammalian system resveratrol plays a crucial role in fighting against several degenerative diseases, which results in extension of life span. Resveratrol fights against 
many diseases of aging, such as cancer, heart diseases, inflammation, brain damage, hearing loss, anorexia and injuries to various tissues [8].

Bauer et al. [61] showed for the first time that resveratrol could extend life span in mammals. In this study, it was found that high-calorie diets (60\% of calories from fat) induced obesity, triggering inflammatory response and comorbidities, such as diabetes and atherosclerosis, which decreased life span in case of middle-aged (1-year-old) mice, but resveratrol treatment $(22.4 \mathrm{mg} / \mathrm{kg} /$ day $)$ along with the high-fat diets extended the life span by inducing Sirt1 similar to calorie-restricted animals with greater SIRT1 coexpression [71]. Evidence is available to show the positive effects of resveratrol and SIRT1 activation on several age-related disorders including type- 2 diabetes, cardiovascular disease, neuro-degeneration and inflammation $[10,61,72,73]$. In yeast, resveratrol was found to activate SIR2 and expand life span about 70\% [67]. Studies have also shown that resveratrol can deacetylate PGC- $1 \alpha$ which is consistent with the activation of SIRT1 [61, 72]. Resveratrol increases longevity through SIRT1, which is activated with $\mathrm{NAD}^{+}$supplied by an anti-aging enzyme PBEF (nampt/visfatin). SIRT1 interacts with an anti-aging transcription factor, FOXO1, which is negatively regulated by Akt. We have shown in one of our recent studies that resveratrol induced the activation of SIRT1, SIRT3 and SIRT4, and the phosphorylation of FOXO1 and FOXO3a as well as PBEF proteins [9]. In this study, we fed a group of rats with resveratrol, red wine and white wine, and we found that levels of SIRT1, SIRT3, SIRT4 and PBEF protein as well as the phosphorylation of FOXO1 and FOXO3a were induced [9]. Thus, resveratrol and red wine can provide protection against age-related cardiac diseases. Furthermore, resveratrol triggers the mammalian cells toward survival by stimulating p53 deacetylation [67], inhibiting adipocyte differentiation, promoting fat mobilization [74] and sensitizing cells to tumor necrosis factor alpha (TNF $\alpha$ )-induced apoptosis by stimulating $\mathrm{NF} \kappa \mathrm{B}$ deacetylation [75]. It is a general opinion that the life span expanding properties of resveratrol is due to its ability to activate SIRT1, but it is also possible that the effects of resveratrol in mammals are only partially mediated by SIRT1. Resveratrol is a well-known regulator of many other enzymes and molecular pathways that might contribute to life span extension and disease suppression [8] which are not related to SIRT1. For example, resveratrol inhibits the insulin pathway independently of SIRT1 [76].

\section{Resveratrol as an anti-aging compound: fact or fiction?}

A growing body of evidence suggests that resveratrol mimics caloric restriction and expands life span. As mentioned earlier, the first scientific evidence originated from the revolutionary observation that resveratrol similar to calorie restriction could activate Sirtl gene [7, 86, 107]. Subsequent studies determined that resveratrol, wines and certain polyphenols could also induce Sirtuins, along with certain other longevity genes including FoxOs and PBEF [9]. More recent studies, however, have questioned the ability of resveratrol to increase life span [10].

The ongoing search for identifying an anti-aging compound has not been successful. To date, calorie restriction is the only effective mean to increase the life span [108], although the mechanisms whereby calorie restriction increases life span remain speculative. Several reports are available in the literature suggesting that exercise and certain chemicals like rapamycin as well as wine could also increase life span [113], although they have not been studied as widely as calorie restriction. A recent study using microarray revealed that out of 6,347 modified genes by calorie restriction, about 58 genes displayed at least twofold alterations in gene expression [109]. There is striking similarities between resveratrol and calorie restriction on the alteration of metabolic pathways. Both resveratrol and calorie restriction improve insulin sensitivity and thus reduce the insulin and glucose levels in the body $[61,72,77]$, which in turn reduce the life-threatening cardiovascular risk factors. Resveratrol and calorie restriction can trigger the expression of GLUT4 [26]. The most important anti-aging gene that is up-regulated by calorie restriction and resveratrol is Sirt1.

In summary, resveratrol has been found to activate several longevity genes, but whether activation of these genes is the cause or consequence is not known. The original report of Sinclair's group with yeast [114] has not been confirmed by subsequent studies [6]. The only study that showed increased life span of mammalians with resveratrol is the study reported by a group of Italian scientists who found resveratrol could increase the life span of fish Nothobranchius furzeri by $56 \%$ [115]. A further study by Sinclair and others showed that resveratrol could not increase longevity of resveratrol-fed mice [116]. In more recent studies, the scientists from two pharmaceutical companies, Pfizer and Amgens, could not verify the results of Sinclair and questioned the effectiveness of resveratrol as an anti-aging compound [116, 117]. A brief description of the longevity genes that have been found to be upregulated by resveratrol is furnished below.

\section{Sirtuins}

The revolutionary finding that resveratrol mimics the effects of calorie restriction in the upregulation of antiaging gene/protein SIRT1 recognized resveratrol as an anti-aging compound [8]. The authors determined that one 
bottle of red wine should consume at least 1,000 to reproduce anti-aging effect of resveratrol. Recent studies, however, indicate that SIRT1 could not only activated by resveratrol or red wine, it was activated with white wine and its components tyrosol and hydroxytyrosol also $[9,96]$. The same study demonstrated that both red and white wines could also activate other sirtuins, SIRT3 and SIRT 4.

SIRT1, which is a NAD ${ }^{+}$-dependent protein deacetylase, may not be directly activated by resveratrol since an artificial SIRT1 substrate, fluor de lys SRT1 could also activate SIRT1 and resveratrol could not activate SIRT1 in vitro in the presence of a acetylated PGC1 $\alpha$. The mechanism of action of SIRT1 is not completely understood. It is believed that SIRT1 deacetylase may directly bind to constituents in the chromatin complex leading to structural reorganization [110].

Several physiological activators of SIRT1 have been identified. For example, increased activation of PNC1, a nicotinamidase converting nicotinamide into nicotinic acid, can activate SIRT 1 in yeast [111]. Enhancement of PBEF/ Nampt/visfatin stimulates cellular NAD thereby increasing the transcriptional activity of catalytic domain of SIRT1 [112]. Whether resveratrol induces SIRT through PNC1 and/or visfatin is not known. SIRT1 can regulate many transcription factors and proteins, and the number of molecular targets for SIRT1 is continuously increasing. It is, however, interesting to note that modulation of the molecular targets by SIRT1 is differentially regulated.

\section{FOXO}

Forkhead box $\mathrm{O}(\mathrm{FOXO})$ is a transcription factor that belongs to the large Forkhead family of proteins and contains a conserved DNA-binding domain termed the 'forkhead box (FOX)' [78]. Four FOXO family members are present in mammals: FOXO1 (or FKHR), FOXO3 (or FKHRL1), FOXO4 (or AFX) and FOXO6 [79]. Not only in mammals, the FOXO transcription factors are present in $C$. elegans and Drosophila elanogaste [79]. FOXO transcription factors are associated with several biological processes like apoptosis, DNA repair, cell cycle arrest, anti-oxidative stress [80, 81]. Studies have shown that FOXO transcription factors increase life span [79, 82-84]. FOXO can shuttle between nucleus and cytoplasm through protein phosphorylation on multiple threonine and serine residues and some accessory proteins such as importins and exportins. It also interacts with 14-3-3 proteins and nuclear transport machinery. Nuclear FOXO interacts with DNA and regulates the transcription of specific target genes through multiple modes of action. After deactivation via phosphorylation or acetylation, it translocates to the cytosol [85]. There are several signaling pathways that can regulate
FOXO transcription factors. Among these, PI3 K-Akt signaling pathway that responds to insulin/IGF-I and several other growth factors [85].

FOXO is a key downstream effector of the PI3 K-Akt pathway [86, 87]. Studies showed that inactivating mutation of insulin receptor (daf-2) or PI3 K (age-1) resulted in extension of life span [88-91]. This extension of life span is reversed when FOXO ortholog daf-16 is mutated [86, 87]. Several studies have shown that Akt can phosphorylate FOXO1, FOXO3 and FOXO4 at The24, Ser256 and Ser319 and inactivate them $[85,92,93]$. When Akt is inactivated and unable to phosphorylate FOXO factors, they remain activated and localized in nucleus. Activated FOXO induced the transcription of several pro-apoptotic genes. When Akt is activated by several growth factors, the FOXO proteins are directly phosphorylated and translocate to the cytoplasm via binding to $14-3-3$ proteins [85, 94], which are a family of cellular chaperones interacting with the protein ligands in a phosphorylation-dependent manner [95]. Thus, by translocating phosphorylated FOXO transcription factors into the cytoplasm, the Akt signaling pathway prevents the transcription of pro-apoptotic genes. Several studies have shown that resveratrol can activate Akt via phosphorylation $[23,96]$ which in turn inactivate FOXOs and translocate into cytoplasm. Not only that, but our own study demonstrated that resveratrol and red wine containing a significant amount of resveratrol can inactivate FOXOs by phosphorylation [9].

Oxidative stress leads to damage and death of cells, so that increase in oxidative stress resistance is related to longevity [97]. Several recent studies have shown that JNK, a member of MAPK superfamily, is a upstream modulator of FOXO factors [98-100]. JNK signaling pathway is known to activate by external stress stimuli. Wang et al. showed for first time that JNK regulates FOXO in Drosophila and plays important role in life span regulation [100]. Another study showed that JNK requires dFOXO, a FOXO ortholog to expand life span [100]. In the same study, it was demonstrated that JNK promotes the nuclear translocation of $\mathrm{dFOXO}$ overexpression of some small heat shock proteins. These heat shock proteins prevent the protein aggregate accumulation due to oxidative stress [100]. Furthermore, JNK activity promotes nuclear translocation of FOXO4 and upregulates the expression of MnSOD [98]. It is clear that Akt and JNK both finally regulate $\mathrm{FOXO}$ activity, but they are working in apposite fashion to promote life span. Akt translocates FOXO into the cytosol and reduces the transcription of pro-apoptotic genes. But JNK translocates FOXO into the nucleus and upregulates some anti-oxidant proteins. However, it is known that resveratrol inhibits the activity of JNK, so it can be assumed that resveratrol modulates FOXO transcription factors via AKT signaling path way. 


\section{PBEF [Visfatin]}

Pre-B cell colony enhancing factor (PBEF), also known as visfatin, is a cytokine that is stress-inducible regulator of $\mathrm{NAD}^{+}$[101]. PBEF is associated with increased Sirtuin activity, suggesting that it could be linked with anti-aging component [9]. I PBEF is also highly expressed in visceral fat of diabetes and obese patients [102]. PBEF is secreted by activated lymphocytes, monocytes and neutrophils and exerts insulin-mimetic effects [103]. A functional equivalent of PBEF, PNC1 is also a longevity gene, whose biochemical activity feeds into the Sirtuin pathway, and is upregulated by mRNA mistranslation [104].

Pre B cell colony enhancing factor has been given a new name visfatin after the discovery that it is preferentially expressed in visceral fat [101]. PBEF/visfatin functions as a nicotinamide phosphoribosyltransferase within the cell, catalyzing the rate-limiting step in the biosynthesis of $\mathrm{NAD}+[105]$. PBEF functions as anti-apoptotic protein and regulates energy metabolism during stress responses [106, 107]. Recently, yeast Sir2 and its mouse ortholog SIRT1 have been found to be NAD-dependent deacetylases based on the finding that SIRT2 can extend life span of yeast, suggesting that NAD could be the missing link between longevity and ATP. A recent study demonstrated increased expression of PBEF with resveratrol and wine [9]. However, our knowledge of the regulation of longevity with PBEF is very limited.

\section{Summary and conclusion}

It should be clear from our discussion that resveratrol, a phytoalexin polyphenolic anti-oxidant, can potentiate diverse functions in the body ranging from gene regulation to cell arrest. Resveratrol acts like a miracle compound, which can protect the cells from many degenerative diseases including cardiovascular complications and cancer. Recent studies implicated resveratrol as an anti-aging compound from the observation that it could mimic the effects of calorie restriction by activating SIRT. Subsequent studies demonstrated activation of several other

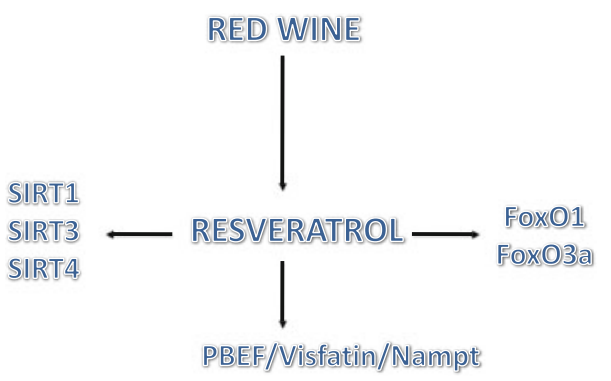

Fig. 2 Induction of the expression of Longevity genes by resveratrol longevity genes by resveratrol including SIRT3, SIRT4, FOXO1, FOXO3a and PBEF (Fig. 2). Recent studies conducted and supported in part by the National Institute of Aging (NIA), however, challenged the ability of resveratrol to increase longevity [10]. The authors determined that resveratrol mimicked some, but not all the effects of calorie restriction in mice. More importantly, resveratrol abolished age-related and obesity-related decline in cardiovascular function including cholesterol level and inflammatory response, but could not affect survival or life span of mice suggesting that resveratrol could not modulate the basic aging process.

Acknowledgements This study was supported by NH HL 34360 , HL22559 and HL33889.

\section{References}

1. Bertelli AA, Das DK (2009) Grapes, wines, resveratrol and heart health. J Cardiovasc Pharmacol 54:468-476

2. Kopp P (1998) Resveratrol, a phytoestrogen found in red wine. A possible explanation for the conundrum of the 'French paradox'? Eur J Endocrinol 38(6):619-620

3. Wang Z, Zou J, Cao K, Hsieh TC, Huang Y, Wu JM (2005) Dealcoholized red wine containing known amounts of resveratrol suppresses atherosclerosis in hypercholesterolemic rabbits without affecting plasma lipid levels. Int $\mathrm{J}$ Mol Med. 16(4):533-540

4. Das DK, Sato M, Ray PS, Maulik G, Engelman RM, Bertelli AA, Bertelli A (1999) Drugs exp. Clin Res 25(2-3):115-120

5. Castello L, Tessitore L (2005) Resveratrol inhibits cell cycle progression in U937 cells. Oncol Rep 13(1):133-137

6. Zhuang H, Kim YS, Koehler RC, Doré S (2003) Potential mechanism by which resveratrol, a red wine constituent, protects neurons. Ann N Y Acad Sci 993:276-286 discussion 287-288

7. Howitz KT, Bitterman KJ, Cohen HY, Lamming DW, Lavu S, Wood JG, Zipkin RE, Chung P, Kisielewski A, Zhang LL, Scherer B, Sinclair DA (2003) Small molecule activators of sirutins extend Saccharomyces cerevisiae lifespan. Nature 425(6954):191-196

8. Baur JA, Sinclair DA (2006) Therapeutic potential of resveratrol: the in vivo evidence. Nat Rev Drug Discov 5(6):493-506

9. Mukherjee S, Lekli I, Gurusamy N, Bertelli AA, Das DK (2009) Expression of the longevity proteins by both red and white wines and their chemoprotective components, resveratrol, tyrosol, and hydroxytyrosol. Free Radic Biol Med 46(5):573-578

10. Pearson KJ, Baur JA, Lewis KN, Peshkin L, Price NL, Labinskyy N, Swindell WR, Kamara D, Minor RK, Perez E, Jamieson HA, Zhang Y, Dunn SR, Sharma K, Pleshko N, Woollett LA, Csiszar A, Ikeno Y, Le Couteur D, Elliot PJ, Becker KG, Navas P, Ingram DK, Wolf NS, Ungvari Z, Sinclair DA, de Cabo R (2008) Resveratrol delays age-related deterioration and mimics transcriptional aspects of dietary restriction without extending life span. Cell Metab. 8(2):157-168

11. Mittlemark BM, Rautaharju PM (1993) Prevalence of cardiovascular diseases among older adults. The Cardiovascular Health Study. Am J Epidemiol 137:311-334

12. Rezzi S, Martin FP, Shanmuganayagam D, Colman RJ, Nicholson JK, Weindruch R (2009) Metabolic shifts due to long-term caloric restriction revealed in nonhuman primates. Exp Gerontol 44(5):356-362 
13. Walford RL (1988) The retardation of aging and disease by dietary restriction. Richard Weindruch, ISBN 0-398-05496-7

14. Mattson MP (2005) Energy intake, meal frequency, and health: a neurobiological perspective. Ann Rev Nutr 25:237-260

15. Richard JL (1987) Coronary risk factors. The French paradox. Arch Mal Coeur Vaiss 80 Spec No:17-21

16. Hattori R, Otani H, Maulik N, Das DK (2002) Pharmacological preconditioning with resveratrol: role of nitric oxide. Am J Physiol Heart Circ Physiol 282:H1988-H1995

17. Cadenas S, Barja G (1999) Resveratrol, melatonin, vitamin E, and $\mathrm{PBN}$ protect against renal oxidative DNA damage induced by the kidney carcinogen $\mathrm{KBrO} 3$. Free Radic Biol Med 26:1531-1537

18. Imamura G, Bertelli AA, Bertelli A, Otani H, Maulik N, Das DK (2002) Pharmacological preconditioning with resveratrol: an insight with iNOS knockout mice. Am J Physiol Heart Circ Physiol 282:H1996-H2003

19. Das S, Alagappan VK, Bagchi D, Sharma HS, Maulik N, Das DK (2005) Coordinated induction of iNOS-VEGF-KDR-eNOS after resveratrol consumption: a potential mechanism for resveratrol preconditioning of the heart. Vascul Pharmacol 42:281-289

20. Fukuda S, Kaga S, Zhan L, Bagchi D, Das DK, Bertelli A, Maulik N (2006) Resveratrol ameliorates myocardial damage by inducing vascular endothelial growth factor-angiogenesis and tyrosine kinase receptor Flk-1. Cell Biochem Biophys 44:43-49

21. Das S, Cordis GA, Maulik N, Das DK (2005) Pharmacological preconditioning with resveratrol: role of CREB-dependent Bcl-2 signaling via adenosine A3 receptor activation. Am J Physiol Heart Circ Physiol 288:H328-H335

22. Das S, Falchi M, Bertelli A, Maulik N, Das DK (2006) Attenuation of ischemia/reperfusion injury in rats by the antiinflammatory action of resveratrol. Arzneimittelforschung 56:700-706

23. Das S, Fraga CG, Das DK (2006) Cardioprotective effect of resveratrol via HO-1 expression involves p38 map kinase and PI-3-kinase signaling, but does not involve NFkappaB. Free Radic Res 40:1066-1075

24. Das S, Tosaki A, Bagchi D, Maulik N, Das DK (2006) Potentiation of a survival signal in the ischemic heart by resveratrol through p38 mitogen-activated protein kinase/mitogen- and stress-activated protein kinase 1/cAMP response element-binding protein signaling. J Pharmacol Exp Ther 317:980-988

25. Dekkers DH, Bezstarosti K, Gurusamy N, Luijk K, Verhoeven AJ, Rijkers EJ, Demmers JA, Lamers JM, Maulik N, Das DK (2008) Identification by a differential proteomic approach of the induced stress and redox proteins by resveratrol in the normal and diabetic rat heart. J Cell Mol Med 12:1677-1689

26. Lekli I, Szabo G, Juhasz B, Das S, Das M, Varga E, Szendrei L, Gesztelyi R, Varadi J, Bak I, Das DK, Tosaki A (2008) Protective mechanisms of resveratrol against ischemia-reperfusioninduced damage in hearts obtained from Zucker obese rats: the role of GLUT-4 and endothelin. Am J Physiol Heart Circ Physiol 294:H859-H866

27. Yen GC, Duh PD, Lin CW (2003) Effects of resveratrol and 4-hexylresorcinol on hydrogen peroxide-induced oxidative DNA damage in human lymphocytes. Free Radic Res 37:509-514

28. Frankel EN, Waterhouse AL, Kinsella JE (1993) Inhibition of human LDL oxidation by resveratrol. Lancet 341:1103-1104

29. Miller NJ, Rice-Evans CA (1995) Antioxidant activity of resveratrol in red wine. Clin Chem 41:1789

30. Hebbar V, Shen G, Hu R, Kim BR, Chen C, Korytko PJ, Crowell JA, Levine BS, Kong AN (2005) Toxicogenomics of resveratrol in rat liver. Life Sci 76:2299-2314

31. Dore S (2002) Decreased activity of the antioxidant heme oxygenase enzyme: implications in ischemia and in Alzheimer's disease. Free Radic Biol Med 32:1276-1282
32. Kim YA, Kim GY, Park KY, Choi YH (2007) Resveratrol inhibits nitric oxide and prostaglandin E2 production by lipopolysaccharide-activated C6 microglia. J Med Food 10:218-224

33. Zhuang H, Kim YS, Koehler RC, Dore S (2003) Potential mechanism by which resveratrol, a red wine constituent, protects neurons. Ann N Y Acad Sci 993:276-286 discussion 287-278

34. Juan SH, Cheng TH, Lin HC, Chu YL, Lee WS (2005) Mechanism of concentration-dependent induction of heme oxygenase1 by resveratrol in human aortic smooth muscle cells. Biochem Pharmacol 69:41-48

35. Olas B, Wachowicz B, Szewczuk J, Saluk-Juszczak J, Kaca W (2001) The effect of resveratrol on the platelet secretory process induced by endotoxin and thrombin. Microbios 105:7-13

36. Orsini F, Pelizzoni F, Verotta L, Aburjai T, Rogers CB (1997) Isolation, synthesis, and antiplatelet aggregation activity of resveratrol 3-O-beta-D-glucopyranoside and related compounds. J Nat Prod 60:1082-1087

37. Soleas GJ, Diamandis EP, Goldberg DM (1997) Resveratrol: a molecule whose time has come? and gone? Clin Biochem 30:91-113

38. Shen MY, Hsiao G, Liu CL, Fong TH, Lin KH, Chou DS, Sheu JR (2007) Inhibitory mechanisms of resveratrol in platelet activation: pivotal roles of p38 MAPK and NO/cyclic GMP. Br J Haematol 139:475-485

39. Jang M, Cai L, Udeani GO, Slowing KV, Thomas CF, Beecher CW, Fong HH, Farnsworth NR, Kinghorn AD, Mehta RG, Moon RC, Pezzuto JM (1997) Cancer chemopreventive activity of resveratrol, a natural product derived from grapes. Science 275:218-220

40. van Ginkel PR, Sareen D, Subramanian L, Walker Q, Darjatmoko SR, Lindstrom MJ, Kulkarni A, Albert DM, Polans AS (2007) Resveratrol inhibits tumor growth of human neuroblastoma and mediates apoptosis by directly targeting mitochondria. Clin Cancer Res 13:5162-5169

41. Trincheri NF, Nicotra G, Follo C, Castino R, Isidoro C (2007) Resveratrol induces cell death in colorectal cancer cells by a novel pathway involving lysosomal cathepsin D. Carcinogenesis 28:922-931

42. Su JL, Yang CY, Zhao M, Kuo ML, Yen ML (2007) Forkhead proteins are critical for bone morphogenetic protein-2 regulation and anti-tumor activity of resveratrol. J Biol Chem 282:19385-19398

43. Harper CE, Patel BB, Wang J, Arabshahi A, Eltoum IA, Lamartiniere CA (2007) Resveratrol suppresses prostate cancer progression in transgenic mice. Carcinogenesis 28:1946-1953

44. Bhardwaj A, Sethi G, Vadhan-Raj S, Bueso-Ramos C, Takada Y, Gaur U, Nair AS, Shishodia S, Aggarwal BB (2007) Resveratrol inhibits proliferation, induces apoptosis, and overcomes chemoresistance through down-regulation of STAT3 and nuclear factor-kappaB-regulated antiapoptotic and cell survival gene products in human multiple myeloma cells. Blood 109:2293-2302

45. Abd El-Mohsen M, Bayele H, Kuhnle G, Gibson G, Debnam E, Kaila Srai S, Rice-Evans C, Spencer JP (2006) Distribution of $[3 \mathrm{H}]$ trans-resveratrol in rat tissues following oral administration. Br J Nutr 96:62-70

46. Sun C, Hu Y, Liu X, Wu T, Wang Y, He W, Wei W (2006) Resveratrol downregulates the constitutional activation of nuclear factor-kappaB in multiple myeloma cells, leading to suppression of proliferation and invasion, arrest of cell cycle, and induction of apoptosis. Cancer Genet Cytogenet 165:9-19

47. Busquets S, Ametller E, Fuster G, Olivan M, Raab V, Argiles JM, Lopez-Soriano FJ (2007) Resveratrol, a natural diphenol, reduces metastatic growth in an experimental cancer model. Cancer Lett 245:144-148 
48. Benitez DA, Pozo-Guisado E, Alvarez-Barrientos A, FernandezSalguero PM, Castellon EA (2007) Mechanisms involved in resveratrol-induced apoptosis and cell cycle arrest in prostate cancer-derived cell lines. J Androl 28:282-293

49. Hwang JT, Kwak DW, Lin SK, Kim HM, Kim YM, Park OJ (2007) Resveratrol induces apoptosis in chemoresistant cancer cells via modulation of AMPK signaling pathway. Ann N Y Acad Sci 1095:441-448

50. Athar M, Back JH, Tang X, Kim KH, Kopelovich L, Bickers DR, Kim AL (2007) Resveratrol: a review of preclinical studies for human cancer prevention. Toxicol Appl Pharmacol 224:274-283

51. Cecchinato V, Chiaramonte R, Nizzardo M, Cristofaro B, Basile A, Sherbet GV, Comi P (2007) Resveratrol-induced apoptosis in human T-cell acute lymphoblastic leukaemia MOLT-4 cells. Biochem Pharmacol 74:1568-1574

52. Kundu JK, Shin YK, Kim SH, Surh YJ (2006) Resveratrol inhibits phorbol ester-induced expression of COX-2 and activation of NF-kappaB in mouse skin by blocking IkappaB kinase activity. Carcinogenesis 27:1465-1474

53. Candelario-Jalil E, de Oliveira AC, Graf S, Bhatia HS, Hull M, Munoz E, Fiebich BL (2007) Resveratrol potently reduces prostaglandin E2 production and free radical formation in lipopolysaccharide-activated primary rat microglia. J Neuroinflammation 4:25

54. Kim YA, Kim GY, Park KY, Choi YH (2007) Resveratrol inhibits nitric oxide and prostaglandin E2 production by lipopolysaccharide-activated C6 microglia. J Med Food 10:218-224

55. Sharma S, Chopra K, Kulkarni SK, Agrewala JN (2007) Resveratrol and curcumin suppress immune response through CD28/CTLA-4 and CD80 co-stimulatory pathway. Clin Exp Immunol 147:155-163

56. Singh NP, Hegde VL, Hofseth LJ, Nagarkatti M, Nagarkatti $P$ (2007) Resveratrol (trans-3, 5, 4'-trihydroxystilbene) ameliorates experimental allergic encephalomyelitis, primarily via induction of apoptosis in $\mathrm{T}$ cells involving activation of aryl hydrocarbon receptor and estrogen receptor. Mol Pharmacol 72:1508-1521

57. Bertelli A, Falchi M, Dib B, Pini E, Mukherjee S, Das DK (2008) Analgesic resveratrol? Antioxid Redox Signal 10:403-404

58. Parker JA, Arango M, Abderrahmane S, Lambert E, Tourette C, Catoire H, Neri C (2005) Resveratrol rescues mutant polyglutamine cytotoxicity in nematode and mammalian neurons. Nat Genet 37:349-350

59. Marambaud P, Zhao H, Davies P (2005) Resveratrol promotes clearance of Alzheimer's disease amyloid-beta peptides. J Biol Chem 280:37377-37382

60. Karlsson J, Emgard M, Brundin P, Burkitt MJ (2000) Transresveratrol protects embryonic mesencephalic cells from tertbutyl hydroperoxide: electron paramagnetic resonance spin trapping evidence for a radical scavenging mechanism. J Neurochem 75:141-150

61. Baur JA, Pearson KJ, Price NL, Jamieson HA, Lerin C, Kalra A, Prabhu VV, Allard JS, Lopez-Lluch G, Lewis K, Pistell PJ, Poosala S, Becker KG, Boss O, Gwinn D, Wang M, Ramaswamy S, Fishbein KW, Spencer RG, Lakatta EG, Le Couteur D, Shaw RJ, Navas P, Puigserver P, Ingram DK, de Cabo R, Sinclair DA (2006) Resveratrol improves health and survival of mice on a high-calorie diet. Nature 444:337-342

62. Miyazaki R, Ichiki T, Hashimoto T, Inanaga K, Imayama I, Sadoshima J, Sunagawa K (2008) SIRT1, a longevity gene, downregulates angiotensin II type 1 receptor expression in vascular smooth muscle cells. Arterioscler Thromb Vasc Biol 28:1263-1269

63. Borra MT, Smith BC, Denu JM (2005) Mechanism of human SIRT1 activation by resveratrol. J Biol Chem 280:17187-17195
64. Kaeberlein M, McDonagh T, Heltweg B, Hixon J, Westman EA, Caldwell SD, Napper A, Curtis R, DiStefano PS, Fields S, Bedalov A, Kennedy BK (2005) Substrate-specific activation of sirtuins by resveratrol. J Biol Chem 280:17038-17045

65. Jiang WJ (2008) Sirtuins: novel targets for metabolic disease in drug development. Biochem Biophys Res Commun 373:341-344

66. Guarente L (2007) Sirtuins in aging and disease. Cold Spring Harb Symp Quant Biol 72:483-488

67. Howitz KT et al (2003) Small molecule activators of sirtuins extend Saccharomyces cerevisiae lifespan. Nature 425:191-196

68. Griswold AJ, Chang KT, Runko AP, Knight MA, Min KT (2008) Sir2 mediates apoptosis through JNK-dependent pathways in Drosophila. Proc Natl Acad Sci USA 105:8673-8678

69. Gruber J, Tang SY, Halliwell B (2007) Evidence for a trade-off between survival and fitness caused by resveratrol treatment of Caenorhabditis elegans. Ann N Y Acad Sci 1100:530-542

70. Terzibasi E, Valenzano DR, Cellerino A (2007) The short-lived fish Nothobranchius furzeri as a new model system for aging studies. Exp Gerontol 42:81-89

71. Nisoli E, Tonello C, Cardile A, Cozzi V, Bracale R, Tedesco L, Falcone S, Valerio A, Cantoni O, Clementi E, Moncada S, Carruba MO (2005) Calorie restriction promotes mitochondrial biogenesis by inducing the expression of eNOS. Science 310:314-317

72. Lagouge M, Argmann C, Gerhart-Hines Z, Meziane H, Lerin C, Daussin F, Messadeq N, Milne J, Lambert P, Elliott P, Geny B, Laakso M, Puigserver P, Auwerx J (2006) Resveratrol improves mitochondrial function and protects against metabolic disease by activating SIRT1 and PGC-1alpha. Cell 127:1109-1122

73. Milne JC, Lambert PD, Schenk S, Carney DP, Smith JJ, Gagne DJ, Jin L, Boss O, Perni RB, Vu CB, Bemis JE, Xie R, Disch JS, $\mathrm{Ng}$ PY, Nunes JJ, Lynch AV, Yang H, Galonek H, Israelian K, Choy W, Iffland A, Lavu S, Medvedik O, Sinclair DA, Olefsky JM, Jirousek MR, Elliott PJ, Westphal CH (2007) Small molecule activators of SIRT1 as therapeutics for the treatment of type 2 diabetes. Nature 450:712-716

74. Picard F, Kurtev M, Chung N, Topark-Ngarm A, Senawong T, De Oliveira RM, Leid M, McBurney MW, Guarente L (2004) Sirt1 promotes fat mobilization in white adipocytes by repressing PPAR-g. Nature 429:771-776

75. Yeung F, Hoberg JE, Ramsey CS, Keller MD, Jones DR, Frye RA, Mayo MW (2004) Modulation of NF-kB-dependent transcription and cell survival by the SIRT1 deacetylase. EMBO J 23:2369-2380

76. Zhang J (2006) Resveratrol inhibits insulin responses in a SirT1independent pathway. Biochem J 397:519-527

77. Blüher M, Kahn BB, Kahn CR (2003) Extended longevity in mice lacking the insulin receptor in adipose tissue. Science 24:572-574

78. Kaestner KH, Knochel W, Martinez DE (2000) Unified nomenclature for the winged helix/forkhead transcription factors. Genes Dev 14:142-146

79. Greer EL, Brunet A (2005) FOXO transcription factors at the interface between longevity and tumor suppression. Oncogene 24:7410-7425

80. Accili D, Arden KC (2004) FoxOs at the crossroads of cellular metabolism, differentiation, and transformation. Cell 117: 421-426

81. Barthel A, Schmoll D, Unterman TG (2005) FoxO proteins in insulin action and metabolism. Trends Endocrinol Metab $16: 183-189$

82. Coffer P (2003) OutFOXing the grim reaper: novel mechanisms regulating longevity by forkhead transcription factors. Sci STKE 2003, PE39

83. Morris BJ (2005) A forkhead in the road to longevity: the molecular basis of lifespan becomes clearer. J Hypertens 23:1285-1309 
84. Huang H, Tindall DJ (2006) FOXO factors: a matter of life and death. Future Oncol 2:83-89

85. Brunet A, Bonni A, Zigmond MJ, Lin MZ, Juo P, Hu LS, Anderson MJ, Arden KC, Blenis J, Greenberg ME (1999) Akt promotes cell survival by phosphorylating and inhibiting a Forkhead transcription factor. Cell 96:857-868

86. Lin K, Dorman JB, Rodan A, Kenyon C (1997) daf-16: An HNF-3/forkhead family member that can function to double the life-span of Caenorhabditis elegans. Science 278:1319-1322

87. Ogg S, Paradis S, Gottlieb S, Patterson GI, Lee L, Tissenbaum HA, Ruvkun G (1997) The Fork head transcription factor DAF16 transduces insulin-like metabolic and longevity signals in $C$. elegans. Nature 389:994-999

88. Johnson TE (1990) Increased life-span of age-1 mutants in Caenorhabditis elegans and lower Gompertz rate of aging. Science 249:908-912

89. Kenyon C, Chang J, Gensch E, Rudner A, Tabtiang R (1993) A C. elegans mutant that lives twice as long as wild type. Nature 366:461-464

90. Morris JZ, Tissenbaum HA, Ruvkun G (1996) A phosphatidylinositol-3-OH kinase family member regulating longevity and diapause in Caenorhabditis elegans. Nature 382:536-539

91. Kimura KD, Tissenbaum HA, Liu Y, Ruvkun G (1997) daf-2, an insulin receptor-like gene that regulates longevity and diapause in Caenorhabditis elegans. Science 277:942-946

92. Biggs WH, Meisenhelder J, Hunter T, Cavenee WK, Arden KC (1999) Protein kinase B/Akt-mediated phosphorylation promotes nuclear exclusion of the winged helix transcription factor FKHR1. Proc Natl Acad Sci USA 96:7421-7426

93. Takaishi H, Konishi H, Matsuzaki H, Ono Y, Shirai Y, Saito N, Kitamura T, Ogawa W, Kasuga M, Kikkawa U, Nishizuka Y (1999) Regulation of nuclear translocation of forkhead transcription factor AFX by protein kinase B. Proc Natl Acad Sci USA 96:11836-11841

94. Brunet A, Kanai F, Stehn J, Xu J, Sarbassova D, Frangioni JV, Dalal SN, DeCaprio JA, Greenberg ME, Yaffe MB (2002) 14-33 transits to the nucleus and participates in dynamic nucleocytoplasmic transport. J Cell Biol 156:817-828

95. Dougherty MK, Morrison DK (2004) Unlocking the code of 14-3-3. J Cell Sci 117:1875-1884

96. Dudley JI, Lekli I, Mukherjee S, Das M, Bertelli AA, Das DK (2008) Does white wine qualify for French paradox? Comparison of the cardioprotective effects of red and white wines and their constituents: resveratrol, tyrosol, and hydroxytyrosol. J Agric Food Chem 56:9362-9373

97. Kirkwood TB, Austad SN (2000) Why do we age? Nature 408:233-238

98. Essers MA, Weijzen S, de Vries-Smits AM, Saarloos I, de Ruiter ND, Bos JL, Burgering BM (2004) FOXO transcription factor activation by oxidative stress mediated by the small GTPase Ral and JNK. EMBO J 23:4802-4812

99. Oh SW, Mukhopadhyay A, Svrzikapa N, Jiang F, Davis RJ, Tissenbaum HA (2005) JNK regulates lifespan in Caenorhabditis elegans by modulating nuclear translocation of forkhead transcription factor/DAF-16. Proc Natl Acad Sci USA 102:4494-4499

100. Wang MC, Bohmann D, Jasper H (2005) JNK extends life span and limits growth by antagonizing cellular and organism-wide responses to insulin signaling. Cell 121:115-125

101. Fukuhara A, Matsuda M, Nishizawa M, Segawa K, Tanaka M, Kishimoto K, Matsuki Y, Murakami M, Ichisaka T, Murakami H, Watanabe E, Takagi T, Akiyoshi M, Ohtsubo T, Kihara S, Yamashita S, Makishima M, Funahashi T, Yamanaka S, Hiramatsu R, Matsuzawa Y, Shimomura I (2004) Visfatin: a protein secreted by visceral fat that mimics the effects of insulin. Science 307(5708):426-430
102. Chen MP, Chung FM, Chang DM, Tsai JC, Huang HF, Shin SJ, Lee YJ (2006) Elevated plasma level of visfatin/pre-B cell colony-enhancing factor in patients with type 2 diabetes mellitus. J Clin Endocrinol Metab 91(1):295-299

103. Luk T, Malam Z, Marshall JC (2008) Pre-B cell colonyenhancing factor (PBEF)/visfatin: a novel mediator of innate immunity. J Leukoc Biol 83(4):804-816

104. Silva RM, Duarte IC, Paredes JA, Lima-Costa T, Perrot M, Boucherie H, Goodfellow BJ, Gomes AC, Mateus DD, Moura GR, Santos MA (2009) The yeast PNC1 longevity gene is upregulated by mRNA mistranslation. PLoS One 4(4):e5212

105. Wang T, Zhang X, Bheda P, Revollo JR, Imai S, Wolberger C (2006) Structure of Nampt/PBEF/visfatin, a mammalian NAD + biosynthetic enzyme. Nat Struct Mol Biol 13(7):661-662

106. Marshall JC, Malam Z, Jia S (2007) Modulating neutrophil apoptosis. Novartis Found Symp 280:53-66 discussion 67-72, $160-164$

107. Barger JL, Kayo T, Vann JM, Arias EB, Wang J, Hacker TA, Wang Y, Raederstorff D, Morrow JD, Leeuwenburgh C, Allison DB, Saupe KW, Cartee GD, Weindruch R, Prolla TA (2008) A low dose of dietary resveratrol partially mimics caloric restriction and retards aging parameters in mice. PLoS One 3(6):e2264

108. Moskovitz J, Bar-Noy S, Williams WM, Requena J, Berlett BS, Stadtman ER (2001) Methionine sulfoxide reductase (MsrA) is a regulator of antioxidant defense and lifespan in mammals. Proc Natl Acad Sci USA 98(23):12920-12925

109. Ruan H, Tang XD, Chen ML, Joiner ML, Sun G, Brot N, Weissbach H, Heinemann SH, Iverson L, Wu CF, Hoshi T (2002) High-quality life extension by the enzyme peptide methionine sulfoxide reductase. Proc Natl Acad Sci USA 99:2748-2753

110. Grubisha O, Smith BC, Denu JM (2005) Small molecule regulation of Sir2 protein deacetylases. FEBS J. 272:4607-4616

111. Anderson RM, Bitterman KJ, Wood JG, Medvedik O, Sinclair DA (2003) Nicotinamide and PNC1 govern lifespan extension by calorie restriction in Saccharomyces cerevisiae. Nature 423(6936):181-185

112. Revollo JR, Grimm AA, Imai S (2004) The NAD biosynthesis pathway mediated by nicotinamide phosphoribosyltransferase regulates Sir2 activity in mammalian cells. J Biol Chem. 279:50754-50763

113. Streppel MT, Ocke MC, Boshulzen HC, Kok FJ, Kromhout D (2009) Long-term wine consumption is related to cardiovascular mortality and life expectancy independently of moderate alcohol intake: the Zutphen Study. J Epidemiol Community Health 63:534-540

114. Howitz KT, Bitterman KJ, Cohen HY, Lamming DW, Lavu S, Wood JG, Zipkin RE, Chung P, Kisielewski A, Zhang LL, Scherer B, Sinclair DA (2003) Small molecule activators of sirtuins extend Saccharomyces cerevisiae lifespan. Nature 425(6954):191-196

115. Pearson KJ, Baur JA, Lewis KN, Peshkin L, Price NL, Labinskyy N, Swindell WR, Kamara D, Minor RK, Perez E, Jamieson HA, Zhang Y, Dunn SR, Sharma K, Pleshko N, Woollett LA, Csiszar A, Ikeno Y, Le Couteur D, Elliott PJ, Becker KG, Navas $\mathrm{P}$, Ingram DK, Wolf NS, Ungvari Z, Sinclair DA, de Cabo R (2008) Resveratrol delays age-related deterioration and mimics transcriptional aspects of dietary restriction without extending life span. Cell Metab. 8:157-168

116. Pacholec M, Chrunyk B, Cunningham D, Flynn D, Griffith D, Griffor M, Loulakis P, Pabst B, Qiu X, Stockman B, Thanabal V, Varghese A, Ward J, Withka J, Ahn K (2010) SRT1720, SRT2183, SRT1460, and resveratrol are not direct activators of SIRT1. J Biol Chem 285:8340-8351

117. Cumine S, Kim KW, Lu S-C, Atangan L, Wang M (2009) Resveratrol is not a direct activator of SIRT1 enzyme activity. Chem Biol Drug Design 74:619-624 